\title{
Anterior Cruciate Ligament Functional Brace Use in Sports*
}

\author{
Edward M. Wojtys, $†$ MD, Sandip U. Kothari, and Laura J. Huston, MS
}

\begin{abstract}
From MedSport and the Section of Orthopaedic Surgery, University of Michigan, Ann Arbor, Michigan
\end{abstract}

\section{ABSTRACT}

The routine use of functional knee braces in the anterior cruciate ligament-deficient, injured, or reconstructed knee, lacks biomechanical support. Although subjective reports favoring bracing are plentiful, objective proof of significant control of tibial translation is not. This in vivo study was designed to assess the effect of six popular braces on anterior tibial translation, isokinetic performance, and neuromuscular function in five chronically unstable anterior cruciate ligament-deficient knees. A knee stress test was performed on a specially designed device that allowed free tibial movement while monitoring anterior tibial translation and muscle function in the quadriceps, hamstring, and gastrocnemius muscles. Results show that braces can decrease anterior tibial translation between $28.8 \%$ and $39.1 \%$ without the stabilizing contractions of the hamstring, quadriceps, and gastrocnemius muscles. With lower extremity muscle activation and bracing, anterior tibial translation was decreased between $69.8 \%$ and $84.9 \%$. Some improvement in spinal level muscle reaction times was seen with brace use, especially in the quadriceps muscle. Unfortunately, most braces appear to consistently slow hamstring muscle reaction times at the voluntary level.

The clinical role of ACL functional braces continues to be defined. Recent investigations have focused on the mechanical function of braces in the prevention of pathologic motion (Refs. 2-4, 9-11, 13, 16, 19, 22, 26, 31-33, 38, 42; R. R. Corn and L. Keppler, unpublished data, 1989; J. C. Kennedy, unpublished data, provided by the Lenox Hill Brace Shop) and on their capacity to reduce strain on the

* Presented at the annual meeting of the AAOS, New Orleans, Louisiana, February 1994

† Address correspondence and reprint requests to Edward M. Wojtys, MD, MedSport, PO Box 363, Ann Arbor, Ml 48106-0363.

No author or related institution has received any financial benefit from research in this study.
ACL in the uninjured knee. ${ }^{5,6}$ Because the objective results of independent brace testing do not agree with the subjective testimonials of many brace users and manufacturers, questions regarding the clinical role of functional braces have increased. ${ }^{25,40}$ Unfortunately, research efforts have not shown functional knee braces capable of eliminating most pathologic anterior-posterior translation or internal-external rotation in the ACL-deficient knee, even at low levels of loading. ${ }^{22,40}$ Consequently, the practice of allowing an individual with an unstable ACL-deficient knee to participate in rigorous sports with a functional brace must be considered hazardous because of the risk of further injury. ${ }^{7,29}$ Because the most common use of an ACL functional brace is to protect a reconstructed or partially torn ACL by attempting to decrease strain in that ligament, proof of that function is needed. Presently, no such data are available.

The idea that braces also function in ways other than providing mechanical restraint to the tibia has been discussed. ${ }^{9,40}$ Proprioceptive augmentation could theoretically improve the dynamic control of unstable knees; there is little doubt that a well-conditioned neuromuscular system can improve the function of an ACL-deficient knee. ${ }^{36,39}$ With these possibilities in mind, the current study was designed to investigate the effect of bracing on neuromuscular function, anterior tibial translation, and isokinetic performance.

\section{MATERIALS AND METHODS}

\section{Subjects}

Five consecutive patients with chronic, complete tears of the ACL confirmed by clinical examination and arthroscopy and having symptoms of instability agreed to participate in this study. Four of these patients had elected nonoperative treatment of their ACL tears and one was awaiting an ACL reconstruction. These patients (four women and one man, average age 32.3 years) were each fitted with six different ACL functional knee braces (Table 1). The braces were fitted by a physical therapist experi- 
TABLE 1

Functional Braces Used in the Study

\begin{tabular}{|c|c|c|}
\hline Brace & Type & Manufacturer \\
\hline Bledsoe Proshifter & Off-the-shelf & $\begin{array}{l}\text { Bledsoe Medical } \\
\text { Technology, Grand } \\
\text { Prairie, Texas }\end{array}$ \\
\hline Donjoy CE 2000 & Custom & $\begin{array}{l}\text { Donjoy Inc., Carlsbad, } \\
\text { California }\end{array}$ \\
\hline Generation II & Custom & $\begin{array}{l}\text { Generation II Orthotics } \\
\text { Inc., Orange, } \\
\text { California }\end{array}$ \\
\hline Lenox Hill Spectralite & Custom & $\begin{array}{l}\text { Lenox Hill Brace Inc., } \\
\text { Long Island, } \\
\text { New York }\end{array}$ \\
\hline Townsend & Custom & $\begin{array}{l}\text { Townsend Design, } \\
\text { Bakersfield, California }\end{array}$ \\
\hline Sutter Talon & Custom & $\begin{array}{l}\text { Sutter Corp., San Diego, } \\
\text { California }\end{array}$ \\
\hline
\end{tabular}

enced in brace fitting according to the manufacturer's strict guidelines. The patients used each brace for several weeks before testing to ensure proper fit and acclimation.

\section{Testing Protocol}

Each patient underwent a subjective functional assessment, ${ }^{27}$ a physical examination of the knee, knee arthrometer measurements without braces (with the KT-1000 arthrometer, MEDmetric Corporation, San Diego, California), isokinetic evaluations of strength and endurance at 60 and $240 \mathrm{deg} / \mathrm{sec}$ with and without knee braces (with the Biodex, Biodex Corp., Shirley, New York), and an anterior tibial translation stress test with electromyographic (EMG) monitoring with and without knee braces. All braces were applied by the subject, according to the manufacturer's guidelines and in the presence of physical therapists experienced in brace use.

\section{Anterior Tibial Translation Stress Test}

The subjects' knees were placed in a specially designed device that allowed anterior tibial translation with and without braces while muscle function was monitored in the medial and lateral quadriceps, medial and lateral hamstring, and gastrocnemius muscles by surface EMG (See Fig. 1, page 428). This tibial translation device has been previously tested for reproducibility and the results published. ${ }^{39}$ The braces were tested in computer-established random order. The knee was positioned at $30^{\circ}$ of flexion and the ankle at $10^{\circ}$ to $15^{\circ}$ of dorsiflexion to simulate in vivo activities. This position was maintained with an ischial support that allowed uninhibited hamstring muscle activity. Thirty pounds of weightbearing was allowed and was monitored with a scale under the subject's foot. The distal femur was firmly held by two condylar supporting pads and the tibia remained unconstrained.

Anterior tibial translation relative to the femur was recorded with two linear potentiometers in response to an anteriorly directed 30-pound step force applied to the posterior aspect of the proximal tibia. Previous work with this system has differentiated between muscle activity gener- ated by the gastrocnemius muscle deformation during tibial loading and the gastrocnemius muscle activity produced in response to anterior tibial translation. ${ }^{39}$ One potentiometer was placed on the patella and the second was placed on the tibial tuberosity.

Muscle activity in the medial and lateral quadriceps, medial and lateral hamstring, and gastrocnemius muscles was simultaneously recorded using bipolar surface electrodes. The bipolar electrodes were placed over the midregion of each muscle group and spaced $3 \mathrm{~cm}$ apart. A Zenith Data Systems 286 computer (Zenith Data Systems, St. Joseph, Michigan) was used to record and analyze all raw EMG signals, which were amplified at $100 \mu \mathrm{V} / \mathrm{V}$. The EMG recordings were sampled at a frequency rate of 1000 $\mathrm{Hz}$ during a 2.5-second period, beginning with the onset of the anteriorly directed force.

Each test consisted of 20 trials; 10 trials with muscles responding and 10 trials with muscles relaxed. During the responding trials, the subjects were asked to resist the displacing tibial force after they felt its onset. During the relaxed trials, subjects were asked not to respond to the tibial displacement by contracting their lower extremity muscles. Muscle activity was monitored by EMG. Premature muscle activity in the response test or inadvertent activity in the muscles-relaxed test led to a repetition of that test. The largest value for anterior tibial translation obtained within the first 2.5 seconds after force application was recorded for each trial. The anterior tibial translation in each of the 10 trials of each subset (response and relaxed) was averaged for each test situation (no brace and with each of the 6 braces) in each subject. The percentage reductions from all five subjects were averaged together to obtain one value for each brace.

\section{Data Analysis}

Muscle Timing. All testing was performed in a random, computer-controlled time sequence. Muscle reaction time was defined as the time delay between the onset of the step force and the initiation of muscle activity. When the subject was ready, the displacing force was initiated at intervals ranging between 0.1 and 10 seconds. These varied time sequences were used to decrease the effects of anticipation by the subject. All visual and audio clues were eliminated.

Three regions of the EMG tracing were analyzed: spinal cord reflex, intermediate response, and voluntary activity. ${ }^{39}$ Each of the muscle activity regions was identified by the shape on the recorded tracing and the relative time of appearance during the 2.5-second sequence that occurred immediately after the force was applied to the posterior aspect of the tibia. Spinal cord reflexes were recorded between 26 and $94 \mathrm{msec}$ after the onset of the anterior force. These reflexes resemble a tendon tap response on physical examination and are usually monophasic with the amplitude of the waveform approximately $5 \%$ of that seen during voluntary activity. The intermediate response was identified within the 117 to $201 \mathrm{msec}$ interval, and voluntary activity occurred within the 192 to $466 \mathrm{msec}$ interval. 
The intermediate response appears to be a spinal reflex, with interneuronal input from centers higher than the spinal cord. This biphasic response is very reproducible, occurring between spinal cord and voluntary activity with an amplitude range between the levels recorded for the spinal cord and voluntary activity. Voluntary activity was always biphasic and of the largest amplitude of the three measured signals. Movement artifact in the EMG signal was identified and eliminated.

Most trials produced a spinal response, and all trials produced a cortical response (intermediate response and voluntary) in each of the five muscle groups. Even though the intermediate response is generated at the spinal cord level, for this investigation it was considered cortical because of the higher central nervous system input needed for its appearance. ${ }^{15}$

The muscles-relaxed trials were analyzed for spinal cord activity only. Therefore, each subject had 20 spinal cord, 10 intermediate response, and 10 voluntary recordings per test. These groups of trials for each muscle were averaged to obtain one number for each phase of activity in each muscle group. Muscle response time was calculated for each muscle group in all five subjects for the spinal cord reflex, intermediate response, and voluntary activity, with and without bracing.

\section{Reproducibility Evaluation}

The reproducibility of this system has been previously reported concerning trial-to-trial (within a test), test-totest (within a day), and day-to-day variability of both the EMG and anterior tibial translation measurements in uninjured subjects without braces. ${ }^{39}$ All statistical significance was determined using a multiway analysis of variance test with repeated measures and post hoc paired $t$-tests. Statistical significance was defined at a level of $P \leq 0.05$.

\section{Isokinetic Strength and Fatigue}

Hamstring and quadriceps muscle strength and fatigue were tested using an isokinetic dynamometer under concentric knee flexion and extension settings. Both extremities were tested before the braces were applied to the ACL-deficient knee. Each test consisted of two subsets of 5 and 20 repetitions at 60 and $240 \mathrm{deg} / \mathrm{sec}$, respectively. The short set was used to evaluate peak torque, and the 20 repetitions were used to evaluate muscle fatigue. After 30 minutes of rest, each subject was retested with the knee brace applied. Previous testing has shown complete muscle recovery occurs after 30 minutes of rest. Consistent verbal encouragement was given during each test to obtain maximal effort. The testing order of the braces was randomly established, and a minimum of 2-days rest was allowed between brace testing sessions. Reproducibility tests on both the uninjured and ACL-deficient extremities with and without braces were conducted during each session and incorporated into the statistical significance evaluation of isokinetic strength.

\section{RESULTS}

\section{Muscle Timing}

Spinal Cord Reflex. Spinal cord level activity was detected in $97 \%$ of the brace and control trials. Many spinal reflex times improved with the application of the knee braces (Table 2). All braces produced improvement in the quadriceps muscle response time (range, 4.8 to $38.6 \mathrm{msec}$ ). The medial quadriceps muscle responses were faster with the application of all six braces, three being statistically significant (Bledsoe, Generation II, and Talon). The lateral quadriceps muscle also performed significantly better with brace application, the changes with two braces were statistically significant (Donjoy and Townsend). The spinal reflex in the lateral hamstring muscle was improved by the application of all six braces (range, 2.4 to 25.2 msec), with the Bledsoe and Townsend braces resulting in significantly faster response times. The medial hamstring muscle response times showed mixed results, with three braces causing improvements and three braces slowing response times. Gastrocnemius muscle performance was minimally affected.

Intermediate Response. Bracing produced inconsistent changes in the intermediate response, with the trend being a slight slowing of the muscle reaction times in most muscle groups. Mixed results were seen in the quadriceps muscle; no brace produced consistent, significant improvement. The gastrocnemius muscle was slowed by all six knee braces; however, the changes were significant with

TABLE 2

Average Change in Muscle Response Times (in milliseconds) ${ }^{\alpha}$

\begin{tabular}{lrrrrc}
\hline \multirow{2}{*}{ Variable } & \multicolumn{5}{c}{ Muscle } \\
\cline { 2 - 6 } & Gastroc. & LH & MH & LQ & MQ \\
\hline Spinal reflex & & & & & \\
Baseline & 43.7 & 71.7 & 64.7 & 91.7 & 71.5 \\
Bledsoe & 8.6 & $-25.2^{b}$ & 19.6 & -19.2 & $-27.9^{b}$ \\
Donjoy & 3.4 & -2.4 & 4.5 & $-27.2^{b}$ & -4.8 \\
Generation II & 8.8 & -4.6 & 3.3 & -20.0 & $-37.5^{b}$ \\
Lenox Hill & 3.0 & -14.2 & -14.8 & -22.0 & -23.8 \\
Talon & 2.0 & -2.8 & -11.0 & -14.4 & $-38.6^{b}$ \\
Townsend & -1.4 & $-16.0^{b}$ & -2.8 & $-31.2^{b}$ & -26.0 \\
Intermediate & & & & & \\
Baseline & 163.6 & 147.4 & 151.5 & 149.7 & 144.8 \\
Bledsoe & 3.8 & 3.0 & -0.8 & 0.1 & -3.1 \\
Donjoy & $11.1^{b}$ & 6.3 & -0.4 & 0.2 & -3.3 \\
Generation II & 0.7 & 3.1 & 5.2 & 0.0 & 9.5 \\
Lenox Hill & $14.1^{b}$ & $12.0^{b}$ & 6.4 & 7.3 & $14.9^{b}$ \\
Talon & 7.1 & 4.4 & 2.3 & -3.0 & -9.7 \\
Townsend & 3.0 & 7.1 & 5.1 & 1.0 & 2.5 \\
Voluntary & & & & & \\
Baseline & 254.7 & 236.6 & 239.6 & 238.1 & 271.6 \\
Bledsoe & $11.5^{b}$ & $16.9^{b}$ & $20.0^{b}$ & $21.5^{b}$ & $33.7^{b}$ \\
Donjoy & 5.8 & 6.0 & $46.2^{b}$ & -3.2 & 11.8 \\
Generation II & -11.1 & 9.4 & 1.9 & $18.3^{b}$ & $36.7^{b}$ \\
Lenox Hill & $-21.2^{b}$ & 5.6 & $36.3^{b}$ & $12.1^{b}$ & $40.2^{b}$ \\
Talon & -6.6 & $17.4^{b}$ & 13.6 & $29.2^{b}$ & $35.8^{b}$ \\
Townsend & $-15.7^{b}$ & 12.2 & $30.4^{b}$ & $18.7^{b}$ & $26.9^{b}$ \\
\hline
\end{tabular}

${ }^{a}$ Change in muscle response time expressed as Brace - No Brace (baseline). Positive numbers indicate that the response time was slower than the baseline, and negative numbers indicate that the response time was faster than the baseline.

${ }^{b}$ Significant at $P<0.05$ level. 
only two braces (Donjoy and Lenox Hill). The Lenox Hill brace was the only one to significantly delay the muscle reaction time of the lateral hamstring, medial quadriceps, and the gastrocnemius muscles.

Voluntary. In general, both quadriceps and hamstring muscle reaction times were slowed by the knee braces. Five braces significantly slowed the muscle reaction times in the medial and lateral quadriceps muscle (Bledsoe, Generation II, Lenox Hill, Talon, and Townsend); the Donjoy brace was the only exception, with insignificant change in the lateral and medial quadriceps muscle. Four braces significantly delayed medial hamstring muscle activity (Bledsoe, Donjoy, Lenox Hill, and Townsend), and two braces significantly slowed lateral hamstring muscle response time (Bledsoe and Talon). The Generation II brace was the only one that did not produce statistically significant slowing of medial or lateral hamstring muscle reaction times.

\section{Anterior Tibial Translation}

In the muscles-relaxed tests, the six knee braces decreased anterior tibial translation by an average of $33.1 \%$ from baseline (range, $28.8 \%$ to $39.1 \%$ ) (Table 3) (Fig. 1). In the muscles-contracted test, the braces were more effective in reducing translation; anterior tibial translation was decreased by an average of $80.1 \%$ from baseline (range, $69.8 \%$ to $84.9 \%$ ). The reduction in anterior tibial translation was significant $(P<0.05)$ in both the musclesrelaxed and muscles-contracted tests.

\section{Isokinetic Testing}

One notable trend was seen in the isokinetic results: brace application decreases hamstring muscle performance (Table 4). With the application of each of the braces, each of the four hamstring muscle test variables showed decreased performance: peak torque/body weight (6 of 6 braces); average work/body weight ( 6 of 6 braces); average power ( 5 of 6 braces); work fatigue ( 5 of 6 braces). The six knee braces reduced the amount of torque generated by an average of $2.4 \%$ in the quadriceps muscle (range, $0.0 \%$ to $5.7 \%$ ); two braces reduced torque significantly (Bledsoe and Lenox Hill). In addition, the torque produced by the hamstring muscle was also inhibited by all six braces, by an average of $5.8 \%$ (range, $0.2 \%$ to $10.7 \%$ ); four reduced

TABLE 3

Anterior Tibial Translation Comparisons with and without Braces

\begin{tabular}{|c|c|c|c|c|}
\hline Condition & $\begin{array}{l}\text { Muscles } \\
\text { relaxed }^{a}\end{array}$ & $\begin{array}{c}\text { Reduction } \\
(\%)\end{array}$ & $\begin{array}{c}\text { Muscles } \\
\text { contracted }^{a}\end{array}$ & $\begin{array}{c}\text { Reduction } \\
\text { (\%) }\end{array}$ \\
\hline No brace & 8.25 & 0.0 & 6.30 & 0.0 \\
\hline Bledsoe & 5.87 & $28.8^{b}$ & 1.10 & $82.5^{b}$ \\
\hline Donjoy & 5.02 & $39.1^{b}$ & 1.32 & $79.1^{b}$ \\
\hline Gen. II & 5.56 & $32.7^{b}$ & 1.23 & $80.4^{b}$ \\
\hline Lenox Hill & 5.61 & $32.0^{b}$ & 1.00 & $84.1^{b}$ \\
\hline Talon & 5.31 & $35.6^{b}$ & 1.90 & $69.8^{b}$ \\
\hline Townsend & 5.74 & $30.4^{b}$ & 0.95 & $84.9^{b}$ \\
\hline
\end{tabular}

${ }^{a}$ Measurements in millimeters.

${ }^{b}$ Indicates significance at $P<0.05$ level.

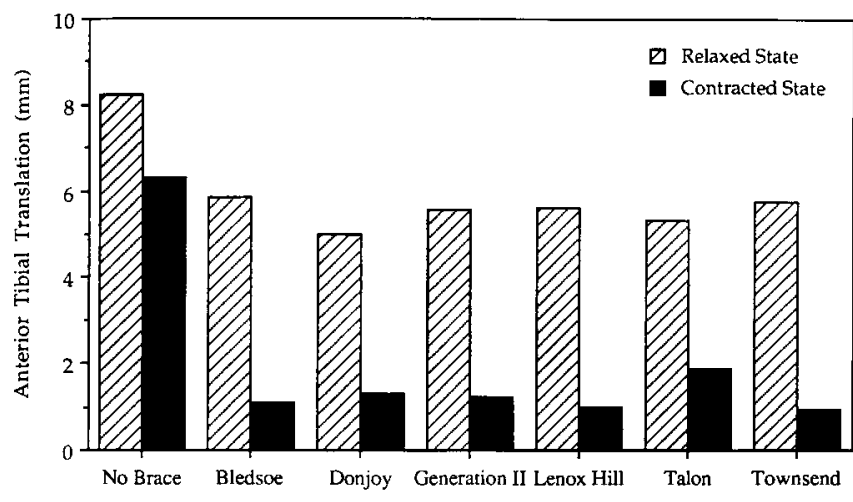

Figure 1. Comparison of average anterior tibial translation between knee braces. Each test was performed at $30^{\circ}$ of flexion with 15 to 30 pounds of weightbearing.

torque significantly (Bledsoe, Lenox Hill, Talon, and Townsend).

In terms of average work/body weight, there was no significant change in the quadriceps muscle performance with brace application, but all six braces produced reductions in hamstring muscle performance (five being significant).

Average power measurements showed no significant change in quadriceps muscle function with five of the six braces, but a significant decrease in hamstring muscle power with four of six braces. Average work fatigue calculations showed no significant positive or negative change in the quadriceps muscle, but hamstring muscle work fatigue rates increased with five of the six braces.

\section{DISCUSSION}

The most important stabilizers of the knee are the quadriceps, hamstring, and gastrocnemius muscles, which cross the joint. Studies by Goldfuss et al., ${ }^{17}$ Markolf et al., ${ }^{24}$ and Wang and Walker ${ }^{37}$ have demonstrated the powerful dynamic effect of these muscles, which can decrease tibial translations and rotations while stiffening the knee joint. This dynamic joint compression system, which protects the knee ligaments, should be preserved or enhanced whenever possible. In fact, this protective joint compression effect should be one of the training and conditioning goals for athletes in rigorous, contact sports. Unfortunately, because this internal protection system is frequently deficient or altered by injury to the knee joint, external supports have become quite popular.

Since the early 1970s, ACL braces have become a common method of attempting to stabilize injured, deficient, or reconstructed knee joints. Clinicians incorporated braces into operative and nonoperative treatment protocols to improve knee stability. Although there is ample subjective evidence of brace function, ${ }^{25,29}$ objective measures are not as favorable. ${ }^{5,6,11}$

The most common use of ACL functional braces today is after reconstructive surgery. However, at this point clinicians must ask themselves, "Is the brace effective in restricting tibial motion and therefore shielding the ACL 
TABLE 4

Isokinetic Performance of Subjects Wearing Different Brace Types ${ }^{a}$

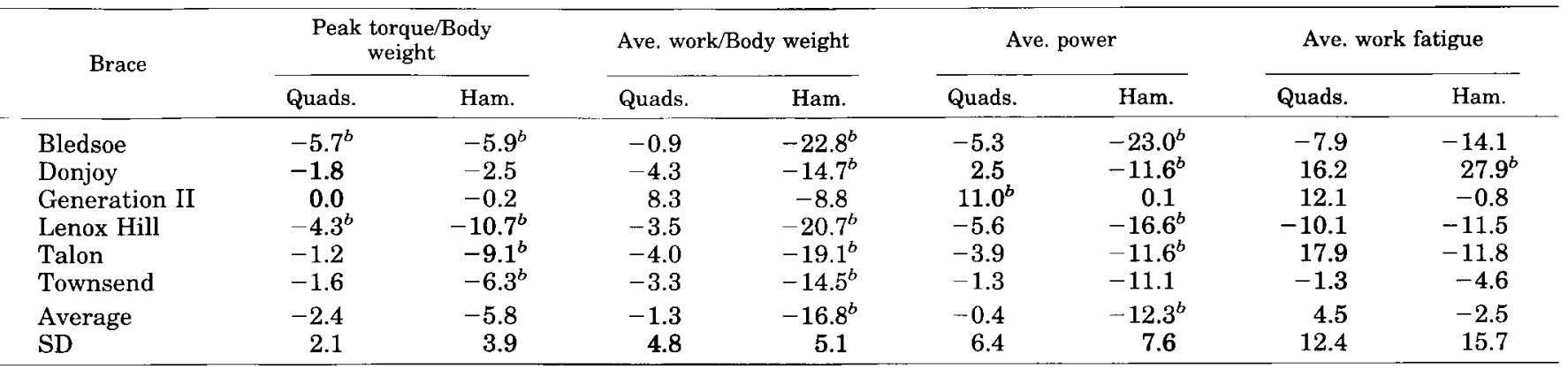

${ }^{a}$ Percent difference $(\%)$-[(Braced - Unbraced)/Unbraced] $\times 100$. Average of four subjects. A negative number indicates a decrease in performance with the brace applied.

${ }^{b}$ Significant value $(P<0.05$ level $)$.

from damaging forces or is it placating the fears and concerns of the surgeon after ACL reconstruction?" Now that the results of operative treatment have improved and the limitations of nonoperative treatment are better defined, ${ }^{7,29}$ it is time to reconsider the clinical role of these costly orthoses.

Because the lower extremity muscles are the most important stabilizers of the knee, it is also important to consider the effects of bracing on lower extremity muscle performance. Branch et al. ${ }^{8}$ used a surface electrode technique to investigate the muscle function of 10 patients with isolated ACL tears and 5 uninjured subjects. They evaluated the effect of the CTi (Innovative Sports, Irvine, California) and Lenox Hill knee braces during a side-step cut maneuver. They were interested in determining whether muscle firing, amplitude, timing, or duration changed with brace application. Branch et al. demonstrated that ACL-deficient patients without braces showed a significant increase in hamstring muscle activity but decreased activity in their quadriceps muscle during testing. When wearing a brace, the patient with an ACL-deficient knee showed a further reduction in the degree of quadriceps muscle activity, along with a decrease in hamstring muscle activity. Muscle timing during cutting maneuvers did not change between the braced and unbraced tests during swing or stance phase. Because the pattern of muscle use did not change with brace application, the investigators concluded that bracing did not augment proprioception. The decrease in muscle activity reported by Branch et al. can be explained in two ways. The braces may have stabilized the knee and subsequently lessened the need for muscle control, or the braces may have directly inhibited the performance of the muscles crossing the knee joint.

Because the hamstring, quadriceps, and gastrocnemius muscles cross the knee joint, they are capable of knee joint stabilization through joint compression. The hamstring muscles have long been considered the most important muscle group in patients with ACL-deficient knees because of their ACL agonist ability, but recent investigations by Lass et al. ${ }^{21}$ have highlighted the importance of the gastrocnemius muscle in stabilizing the ACL-deficient knee. The functional role of the quadriceps muscle in an
ACL-deficient knee, however, remains poorly defined. In simple terms, the quadriceps muscle is an ACL antagonist. Therefore, isolated, strong, quick quadriceps muscle contractions seem unwanted. However, true isolated quadriceps muscle responses probably rarely occur in vivo.

Balanced quadriceps muscle activity is needed in the ACL-deficient knee to restore a normal gait pattern after $\mathrm{ACL}$ injury, ${ }^{29}$ but eccentric quadriceps muscle function plays an important role in shock absorption during axial loading of the lower extremity. Because very little is known about the effects of combined muscle activity patterns, further investigation is needed into the effects of muscle co-contraction on joint stabilization and shock absorption in the ACL-deficient knee. At this point, it is not known which muscle response pattern is best suited to control anterior tibial translation during daily activities or sports. Furthermore, the time sequence parameters for muscle responses needed to prevent injury remain unknown.

The clinical significance of the degree of change seen in the muscle reaction time in this study remains in question but is cause for concern (Table 2). The delays in voluntary muscle response time in this study are of the same magnitude as the time sequence from force application to ACL failure in an in vitro model. ${ }^{41}$ Although these data are preliminary because only five subjects were tested with braces in this study, the differences in the muscle reaction times reported here imply that further investigation is reasonable. If significant muscle reaction time slowing is produced by functional braces, especially in the hamstring muscle, there is cause for concern, especially in competitive athletes.

Several investigators have documented the importance of good hamstring muscle function in preventing abnormal anterior tibial translation in stable and unstable knees. ${ }^{34,36,39}$ Walla et al. ${ }^{36}$ examined 38 patients who had nonoperative treatment of ACL tears for at least 24 months. Their goal was to identify the parameters that would provide the examining physician with guidelines for selecting the appropriate course of management for each patient after an ACL tear. They concluded that in the ACL-deficient knee, the presence of "reflex level" ham- 
string muscle control was most closely associated with high functional rating scores. Interestingly, the power and strength measurements in that group of patients did not correlate well with the functional status of the knee.

Wojtys and Huston ${ }^{39}$ showed a direct correlation between hamstring muscle function and subjective and objective knee performance in 100 patients with ACL-deficient knees and 40 uninjured subjects. The functional rating of most knees was directly related to the subject's ability to initiate a stabilizing hamstring muscle contraction during anterior tibial translation.

Bagger et al. ${ }^{1}$ evaluated the effect of functional knee bracing on quadriceps and hamstring muscle EMG activity during anterior tibial translation in an ACL-deficient knee. Using a computerized electrogoniometer system, they concluded that anterior tibial translation was significantly reduced by hamstring muscle activity in all three knee flexion positions tested.

Based on the conclusions of these studies, it is likely that the hamstring muscles are capable of protecting an ACL graft by relieving strain in the postoperative setting. ${ }^{1,36,39}$ Therefore, enhancement of this ability should be part of all rehabilitation protocols after ACL injury or reconstruction, and eliminating or minimizing inhibition of hamstring muscle function seems advisable.

In this study, bracing appeared to improve spinal reflex time in response to anterior tibial translation to some extent (Table 2). All six braces produced improvement in the lateral hamstring muscle times, and two braces improved medial hamstring muscle function. Unfortunately, only 2 of those 12 changes in hamstring muscle function were statistically significant. Quadriceps muscle function, however, improved in all 12 categories at the spinal reflex level, with five changes being statistically significant. Although the improvement in hamstring muscle function seems desirable, improved reaction time of the quadriceps muscle may be unwanted and may have an undesirable effect on anterior tibial translation if not balanced by simultaneous hamstring or gastrocnemius muscle activity.

At the voluntary muscle reaction time sequence (Table 2 ), the very frequent slowing of the muscle reaction times, especially of the hamstring muscles, is a persistent concern, especially for those athletes in sports requiring pivoting, quick starting, and stopping. Although it may represent only a minor or no concern for those patients using the brace for activities of daily living, for those in rigorous or contact sports, the delay in voluntary muscle reaction time may change the outcome during an injury situation. Interestingly, the brace that produced the largest decrease in anterior tibial translation when muscles were relaxed, the Donjoy, also produced the longest delay in voluntary hamstring muscle reaction time. With ACL functional bracing, this may be the price paid for improved tibial translational control. Further research on the preferred muscle response to anterior tibial translation at the spinal cord and cortical level should help clarify this issue.

Because biomechanical data on ACL strain reduction with bracing does not support the routine use of functional knee bracing in ACL-deficient, injured, or reconstructed knees, the use of ACL functional braces in these situations must be justified in some manner. ${ }^{5,6}$ If functional knee braces are not capable of restricting pathologic tibial-femoral motion adequately during high stress activities, their routine use in the postinjury or postoperative setting may be exposing patients to unreasonable risks by providing them with a false sense of security. Current work by Beynnon et al. ${ }^{5,6}$ casts doubt on the possibility that braces can relieve in vivo ACL strain at functional loads. However, it is important to note that this work was performed on knees with normal ACLs using a Hall effect transducer. How these studies relate to an ACL that is injured or reconstructed is unknown. Nevertheless, at present we are unaware of any objective evidence that functional knee braces can reduce strain in an ACL graft. If an ACL load-dampening effect could be documented, it may justify postoperative ACL functional bracing. In the absence of such mechanical justification or evidence of protection, the possibility of muscle inhibition by bracing warrants further caution and investigation.

In terms of isokinetic performance, other studies have examined the effect of functional knee braces in athletes. ${ }^{18,23}$ Houston and Goemans ${ }^{18}$ examined seven male athletes with various knee problems, including medial and anterior instability. Three braces were used: the Lenox Hill brace in four patients, the Toronto brace in one, and the Kelly brace in two. The mean maximal torque output during isokinetic knee extension contractions with braces was found to decrease by $12 \%$ to $30 \%$. The differences between the braced and unbraced conditions increased at the faster speeds of testing. Interestingly, the maximal attained velocity in knee extension was $20 \%$ higher when the patients did not wear the brace, and the vertical velocity during a short, all-out stair run was also slower in patients wearing braces. All of these patients were thoroughly accustomed to their prescribed braces, having worn them during athletic training and competitions as well as during work and recreational activities. In spite of this familiarity, performance measures during all of the dynamic one- and two-legged tests were poor for all patients while wearing braces. Of note is the fact that a 15-minute ergometer bicycle ride with and without knee braces showed that lactate concentrations were $41 \%$ higher in patients who wore the knee braces.

Most isokinetic muscle parameters in this study (peak torque, average work, average power, work fatigue) did not improve with bracing. Only one category (quadriceps muscle average work fatigue) improved with bracing. The improvement was not statistically significant.

Of particular interest in this study was the performance of the Generation II brace, which was the only singlehinge brace in this study. The Generation II brace did not produce a significant decrease in anterior tibial translation with muscles contracted or in any of the isokinetic performance parameters, and it was the only brace that did not produce a significant slowing of the hamstring muscles in the three phases of the muscle reaction time. Marans et al. ${ }^{23}$ also used functional testing to evaluate the Generation II brace in a study of both subjective and objective parameters in 10 chronic, unilateral, symptom- 
atic ACL-deficient knees with three custom and three off-the-shelf braces. The authors concluded that the laterally hinged braces were as effective as the more commonly used double-hinged models. In the study by Marans et al., the Lenox Hill and Generation II braces were the only braces to improve performance of ACL-dependent activities, but all of the braces impaired the subject's ability to run straight ahead. The most subjectively restrictive brace (the Donjoy) impaired running the most. Because the McDavid knee guard (McDavid Knee Guard Inc., Clarendon Hills, Illinois) and Generation II braces (lateral hinge only) did as well as the double-hinge braces, Marans et al. concluded that there was no advantage to the more expensive double-hinge braces.

Conversely, performance testing on some double-hinged braces in select situations has been quite impressive. Cook et al. ${ }^{12}$ examined the effect of the CTi brace on 14 ACLdeficient athletes while running and cutting. They used high-speed photography and force plate analysis. The results were very encouraging, with an increase in running velocity while wearing the brace reported. Unfortunately, the majority of studies, when comparing braces side by side, actually show no change or a decrease in performance. ${ }^{19,25,30,32,35}$

The anterior tibial translation reduction data in this study (Fig. 1) suggests that muscle contraction augments the ability of the brace to control tibial motion, because the best control of anterior tibial translation occurred when braces were used and the muscles were contracted. This muscle activity most likely improved the brace-soft tissuebone interface, providing a more rigid thigh and leg composite. Unfortunately, we cannot be certain when or if this idealized situation occurs in vivo. It is not known if those patients with ACL-deficient knees who are plagued by giving way episodes can generate hamstring, quadriceps, and gastrocnemius muscle contractions when needed. In fact, data from this study indicate a generalized slowing of the hamstring muscle at the intermediate and voluntary level when braces were used, resulting in further questions about the status of these important stabilizers when needed the most.

An important factor to consider when evaluating brace data obtained during testing is the level of force used to induce tibial displacements. The level of force used in this study, compared with those anticipated during activities of daily living and rigorous sports, ${ }^{28}$ was quite low (30 pounds, or $133 \mathrm{~N}$ ). Markolf et al. ${ }^{24}$ reported that a force of at least $200 \mathrm{~N}$ (45 pounds) would be needed just to overcome the stiffness of the soft tissues crossing the knee when evaluating anterior tibial translation and the effect of bracing on a knee with a reconstructed or injured ACL. Patient safety prevented the use of these anterior displacement forces in our testing system. Based on the results of previous studies, less tibial control would be expected with higher anterior displacement forces.

Another cause for concern with the use of ACL functional braces is the increased axial forces Devita et al, ${ }^{14}$ and Knutzen et al. ${ }^{20}$ reported during gait with bracing. This factor may be most important in those patients with chondral defects and meniscal loss. The "quadriceps avoid- ance gait" seen in patients with ACL-deficient knees ${ }^{35}$ and the further decrease in quadriceps muscle function reported with bracing ${ }^{9}$ suggest a possible decrease in negative quadriceps muscle work performed (shock absorption), which could result in higher axial forces at foot strike. The inhibition of this protective mechanism could accelerate degenerative changes as a result of increasing impact loading.

In terms of today's postoperative ACL scenario, current methods of aggressive rehabilitation can produce near normal motion and strength in 3 to 6 months after ACL reconstruction. The dilemma facing the clinician then becomes when to allow jumping, turning, twisting, or contact sports. This is a complex decision that should be based on several factors, including the strength of the ACL graft and the known biological factors affecting healing, graft fixation, and the success of rehabilitation efforts. A knee joint adequately stabilized with a strong, isometric graft should not need a functional brace to prevent pathologic motion in a controlled rehabilitation environment. Furthermore, it is unknown whether graft stretching can be prevented by brace use in the early phases of graft revascularization and maturation. If functional braces do not reduce ACL strain or augment proprioception, ${ }^{8}$ if they do increase vertical impact loading, and, in fact, inhibit knee joint muscle stabilizing activity, then the routine use of functional knee bracing in ACL-reconstructed or deficient knees should be seriously questioned.

On the other hand, it is possible that the positive subjective results seen with bracing are due to a stiffening of the entire lower extremity, which decreases the likelihood of large extension torques at the knee that may precipitate subluxation or giving way episodes in the absence of adequate muscle stabilization. Further studies on functional bracing may benefit from examining this bracing effect on the entire extremity from hip to ankle. Also, if an ACL stress-shielding effect can be demonstrated by bracing in a reconstructed or injured knee, then this benefit may outweigh the apparent negative effects on muscle function. However, at this point, no such proof of ACL protection is available.

\section{SUMMARY}

The routine use of ACL functional braces in sports needs to be researched further because it is difficult to justify on the basis of biomechanical data currently available. Although the tibial control data reported here are encouraging, these studies were performed at low levels of force ( 30 pounds). It is not known what degree of tibial control is present at higher, functional levels. In terms of the delays in voluntary muscle reaction time with brace use, it can be argued which is more important, tibial control or muscle inhibition, especially during activities of daily living. Finally, data on the ACL strain-reducing capability of braces in the reconstructed knee are lacking. This information could help further determine the role of functional bracing after ACL injury or surgery. 


\section{REFERENCES}

1. Bagger J, Ravn J, Lavard $P$, et al: Effect of functional bracing, quadriceps and hamstrings on anterior tibial translation in anterior cruciate ligament insufficiency: A preliminary study. J Rehabil Res Dev 29: 9-12, 1992

2. Baker BE, Van Hanswyk E, Bogosian S, et al: A biomechanical study of the static stabilizing effect of knee braces on medial stability. Am $J$ Sports Med 15: 566-570, 1987

3. Bassett GS, Fleming BW: The Lenox Hill Brace in anterolateral rotatory instability. Am $J$ Sports Med 11: 345-348, 1983

4. Beck C, Drez D Jr, Young J, et al: Instrumented testing of functional knee braces. Am J Sports Med 14: 253-256, 1986

5. Beynnon $B D$, Fleming $B C$, Peura $G D$, et al: An in-vivo investigation of anterior cruciate ligament strain: The effect of functional knee bracing and attachment strap tension. Trans Orthop Res Soc 20: 94, 1995

6. Beynnon $\mathrm{BD}$, Pope $\mathrm{MH}$, Wertheimer $\mathrm{CM}$, et al: The effect of functional knee-braces on strain on the anterior cruciate ligament in vivo. $J$ Bone Joint Surg 74A: 1298-1312, 1992

7. Bonamo JJ, Fay C, Firestone T: The conservative treatment of the anterior cruciate deficient knee. Am J Sports Med 18:618-623, 1990

8. Branch TP, Hunter R, Donath M: Dynamic EMG analysis of anterior cruciate deficient legs with and without bracing during cutting. Am J Sports Med 17: 35-41, 1989

9. Branch TP, Hunter R, Reynolds P: Controlling anterior tibial displacement under static load: A comparison of two braces. Orthopedics 11: 12491252,1988

10. Butler PB, Evans GA, Rose GK, et al: A review of selected knee orthoses. Br J Rheumatol 22: 109-120, 1983

11. Colville MR, Lee CL, Ciullo JV: The Lenox Hill Brace: An evaluation of effectiveness in treating knee instability. Am J Sports Med 14: 257-261, 1986

12. Cook FF, Tibone JE, Redfern FC: A dynamic analysis of a functional brace for anterior cruciate ligament insufficiency. Am J Sports Med 17:519-524, 1989

13. Coughlin L, Oliver J, Berretta G: Knee bracing and anterolateral rotatory instability. Am J Sports Med 15: 161-163, 1987

14. Devita $P$, Hunter PB, Skelly WA: Effects of a functional knee brace on the biomechanics of running. Med Sci Sports Exerc 24: 797-806, 1992

15. Eccles JC: Evolution of the brain: Creation of the self, in Evolution of the Brain. New York, Routledge, 1989, pp 61-67

16. Gerber C, Jakob RP, Ganz R: Observations concerning the limited mobilisation cast after anterior cruciate ligament surgery. Arch Orthop Trauma Surg 101: 291-296, 1983

17. Goldfuss AJ, Morehouse CA, LeVeau BF: Effect of muscular tension on knee stability. Med Sci Sports 5: 267-271, 1973

18. Houston ME, Goemans PH: Leg muscle performance of athletes with and without knee support braces. Arch Phys Med Rehabil 63: 431-432, 1982

19. Jonsson H, Kärrholm J: The stabilizing effect of the knee braces after anterior cruciate ligament rupture. Acta Orthop Scand (Suppl) 231: 29, 1989

20. Knutzen KM, Bates BT, Schot $P$, et al: A biomechanical analysis of two functional knee braces. Med Sci Sports Exerc 19: 303-309, 1987

21. Lass $P$, Kaalund $S$, leFevre $S$, et al: Muscle coordination following rupture of the anterior cruciate ligament. Electromyographic studies of 14 patients. Acta Orthop Scand 62: 9-14, 1991
22. Liu SH, Lunsford T, Gude $S$, et al: Comparison of functional knee braces for control of anterior tibial displacement. Clin Orthop 303:203-210, 1994

23. Marans $\mathrm{HJ}$, Jackson RW, Piccinin $J$, et al: Functional testing of braces for anterior cruciate ligament-deficient knees. Can J Surg 34: 167-172, 1991

24. Markolf KL, Kochan A, Amstutz HC: Measurement of knee stiffness and laxity in patients with documented absence of the anterior cruciate ligament. J Bone Joint Surg 66A: 242-253, 1984

25. Mishra DK, Daniel DM, Stone ML: The use of functional knee braces in the control of pathologic anterior knee laxity. Clin Orthop 241:213-220, 1989

26. Mortensen WW, Foreman K, Focht $L$, et al: An in vitro study of functional orthoses in the ACL disrupted knee. Trans Orthop Res Soc 13: 520, 1988

27. Noyes FR, Barber SD, Mangine RE: Bone-patellar ligament-bone and fascia lata allografts for reconstruction of the anterior cruciate ligament. $J$ Bone Joint Surg 72A: 1125-1136, 1990

28. Noyes FR, Butler DL, Grood ES, et al: Biomechanical analysis of human ligamant grafts used in knee-ligament repairs and reconstructions. $J$ Bone Joint Surg 66A: 344-352, 1984

29. Noyes FR, Schipplein OD, Andriacchi TP, et al: The anterior cruciate ligament-deficient knee with varus alignment. An analysis of gait adaptations and dynamic joint loadings. Am J Sports Med 20: 707-716, 1992

30. Rink PC, Scott RA, Lupo RL, et al: $A$ comparative study of functional bracing in the anterior cruciate deficient knee. Orthop Rev 18: 719-727, 1989

31. Roser LA, Miller SJ, Clawson DK: Effects of taping and bracing on the unstable knee. Northwest Med 70: 544-546, 1971

32. Tegner $\mathrm{Y}$, Lysholm J: Derotation brace and knee function in patients with anterior cruciate ligament tears. Arthroscopy 1: 264-267, 1985

33. Tegner $Y$, Pettersson $G$, Lysholm J, et al: The effect of derotation braces on knee motion. Acta Orthop Scand 59: 284-287, 1988

34. Tibone JE, Antich TJ, Fanton GS, et al: Functional analysis of anterior cruciate ligament instability. Am J Sports Med 14: 276-284, 1986

35. Vailas JC, Pink $M$ : Biomechanical effects of functional knee bracing Practical implications. Sports Med 15: 210-218, 1993

36. Walla DJ, Albright JP, McAuley E, et al: Hamstring control and the unstable anterior cruciate ligament-deficient knee. Am J Sports Med 13: 34-39, 1985

37. Wang CJ, Walker PS: Rotatory laxity of the human knee joint. J Bone Joint Surg 56A: 161-170, 1974

38. Wojtys EM, Goldstein SA, Redfern M, et al: A biomechanical evaluation of the Lenox Hill Knee Brace. Clin Orthop 220: 179-184, 1987

39. Wojtys EM, Huston LJ: Neuromuscular performance in normal and anterior cruciate ligament-deficient lower extremities. Am J Sports Med 22: 89-104, 1994

40. Wojtys EM, Loubert PV, Samson SY, et al: Use of a knee-brace for control of tibial translation and rotation. J Bone Joint Surg 72A: 1323-1329, 1990

41. Yasuda $\mathrm{K}$, Erickson AR, Beynnon BD, et al: Dynamic elongation behavior in the medial collateral and anterior cruciate ligaments during lateral impact loading. J Orthop Res 11: 190-198, 1993

42. Zogby RG, Baker BE, Seymour RJ, et al: A biomechanical evaluation of the effect of functional braces on anterior cruciate ligament instability using the Genucom knee analysis system. Trans Orthop Res Soc 14:212, 1989 